\title{
CONTORNOS DAS POLÍTICAS SOCIAIS (ASSISTÊNCIA- EDUCAÇÃO) À INFÂNCIA DESVALIDA PORTUGUESA (SÉCULOS XIX E XX)
}

\author{
CONTOURS OF SOCIAL POLICIES (ASSISTANCE-EDUCATION) TO \\ PORTUGUESE DISABLED CHILDHOOD (19TH-20TH CENTURY)
}

\author{
Ernesto Candeias Martins \\ Doutor com título de Agregação Universitária \\ Castelo Branco - Portugal \\ ernesto@ipcb.pt
}

\begin{abstract}
Resumo: A problemática da assistência e educação às crianças pobres, abandonadas ou desvalidas, designadas por 'Outra infância', apresentou diferentes enfoques de análise e diferentes discursos, que tiveram respostas sociais (políticas), segundo o período histórico abordado (século XIX e parte do século XX). O propósito historiográfico norteia-se pela assistência educativa e protetiva àquele tipo de infância. Recorremos a fontes documentais, à imprensa, a legislação, a teses e monografias de instituições, etc., que permitiram elaborar a argumentação, de índole hermenêutica, que é um método cujo campo de atuação envolve a compreensão e a profundidade dos aspetos subjetivos e objetivos de pesquisa. O quadro teórico-conceptual assenta numa base ampla de referências à proteção e assistência social, à economia social, aos dispositivos jurídicos, ao papel das instituições asilares de internamento, etc. A estrutura do estudo divide-se em 3 pontos: a representação social da infância e respetivas construções sociais; a assistência social regulada pelos dispositivos administrativos locais e a perspetiva das instituições de internação à infância desvalida.
\end{abstract}

Palavras-chave: Infância desvalida. Assistência educativa. Políticas sociais. Instituições de internação. Criança abandonada.

\begin{abstract}
The problem of care and education to poor, abandoned or disabled children, called 'Another childhood', presented different approaches of analysis and discourses, which had social (political) responses, according to the historical period, addressed (19th and part of the 20th century). The historiographic purpose is guided by educational and protective care for that type of childhood. We used documentary sources, the press, legislation, theses and monographs of institutions, etc. that allowed the development of the argumentation, of hermeneutic nature, which is a method whose field of action involves the understanding and depth of subjective aspects and research objectives. The theoretical-conceptual framework is based on a broad basis of references to protection and social assistance, social economy, legal provisions, the role of nursing homes institutions, etc. The structure of the study is divided into 3 points: the social representation of childhood and its social constructions; social assistance regulated by local administrative arrangements; perspective of institutions from hospitalization to childhood is invalidated.
\end{abstract}

Keywords: Childhood is invalidated. Educational assistance. Social policies. Institutions in internment. Abandoned child.

\section{Para citar - ABNT NBR 6023:2018}

MARTINS, Ernesto Candeias. Contornos das políticas sociais (assistência-educação) à infância desvalida portuguesa (séculos XIX e XX). Cadernos de Pós-graduação, São Paulo, v. 19, n. 2, p. 146-158, jul./dez. 2020. Disponível em: https://doi.org/10.5585/cpg.v19n2.16823. 


\section{Introdução}

A problemática da assistência e educação às crianças abandonadas, pobres ou desvalidas, apresenta diferentes enfoques de análise, que tiveram respostas sociais liberais (Monarquia Constitucional) a essas situações de mendicidade, pobreza, vagabundagem e de marginalidade até à publicação de legislação e criação de instituições de internação que as acolhessem, assistissem e educassem na base de conceções definidas com vista à sua inserção na sociedade. Assim, foram surgindo as políticas de proteção social e de integração, por parte do Estado, até culminarem com a Lei de Proteção à Infância em 1911, que deu início ao direito tutelar de menores e respetivas medidas assistenciais e jurídicas.

Pretendemos abordar historiograficamente a assistência educativa e protetiva àquele tipo de 'infância', a qual designamos por 'Outra infância', distinguindo-a, no seu processo de socialização, escolarização e situações sociais e familiares, da dita infância 'normal', que tinha um percurso normalizado para a desejada coesão social das políticas do governo monárquico (liberal). O nosso arco histórico percorre o século XIX até às primeiras décadas do século XX, que é um período durante o qual o abandono, a marginalização e os conflitos sociais dessa infância alcançam cotas significativas (detenção), o que implicou o surgimento de medidas específicas de proteção e profilaxia, justificadas segundo a informação documental existente. Recorremos a algumas fontes documentais (primárias e secundárias), à imprensa, à legislação, a teses e monografias de instituições, etc., que permitiram elaborar a argumentação, de índole hermenêutica. Este é um método cujo campo de atuação envolve a compreensão e o aprofundamento dos aspetos subjetivos e objetivos do problema de pesquisa. É uma ferramenta teórica e metodológica que permite analisar o contexto socio-histórico e espácio-temporal da assistência educativa à infância, na base de análises discursivas e de conteúdo, tendo em conta a ideologia como vertente social, importante naquele período histórico (THOMPSON, 2011). Servimo-nos dessa interpretação da doxa (hermenêutica da vida quotidiana), segundo Thompson, para construir a representação social daquela 'Outra infância' e da sua contextualização. Deste modo, dividimos o estudo em 3 pontos: a representação social da infância e as respetivas construções e conceções sociais; a assistência social dada através da regulação dos dispositivos administrativos locais-e a perspetiva das instituições de internação para acolher, assistir e educar a infância desvalida.

O nosso quadro teórico-conceptual, numa base mais ampla, norteia-se por publicações de referência de enquadramento para compreendermos a historiografia da proteção social, por exemplo: G. Thuillier (2003), que analisa os princípios e temáticas subjacentes ao entendimento da proteção social; A. Gueslin (1987), sobre a 'economia social' (=atual termo de proteção social), relacionando-a com caridade e filantropia e analisando o papel das cooperativas, mutualidades, 
associações, sindicatos e instituições, ou seja, os organismos de teor preventivos ou de previdência; C. Bec (1994), no estudo às filantropias e políticas sociais na Europa; M. Antónia Lopes (2010), abordando a proteção social portuguesa e o papel das misericórdias no século XIX até à 1 . $^{2}$ República (LOPES; SÁ, 2008), etc. Este campo conceptual da assistência social foi também tratado no campo da (Nova) História de Portugal (séculos XIX e XX) (MARQUES; RODRIGUES, 1991), com incidência sobre a pobreza (COSTA, 1985 e 1998), a mendicidade, os órfãos e os expostos (FONTE, 2004) e, ainda, a ação das misericórdias nesse sistema (LOPES; PAIVA, 2010; MARTINS, 1999), na assistência à infância (CALDEIRA, 1993), às famílias indigentes e mendigas e aos presos, cuja intervenção social se confundia com assistência-repressão (LOPES; SÁ, 2008), ou seja, o papel da intervenção do Estado neste plano de políticas sociais (PEREIRA, 2012), etc. De facto, o aparecimento dos vários estudos referidos permite-nos interpretar as respostas sociais às carências das famílias portuguesas e os impactos nas crianças, o que originou o aparecimento de dispositivos legais e de iniciativas caritativas e beneficentes, a criação de instituições (asilos, casas de correção, colónias agrícolas, etc.), para além das medidas de repressão, correção e regeneração da infância.

$\mathrm{Na}$ verdade, até finais do século XIX, a proteção às crianças era assegurada, maioritariamente, por instituições de caridade e beneficência (misericórdias, hospitais, hospícios, recolhimentos, orfanatos, asilos, etc.) com o intuito de regenerar e ressocializar essas crianças pela instrução, higiene, trabalho, moral e religião. Assim se apregoou a ideia de salvar as crianças como uma forma de profilaxia social, tanto ao nível escolar, quanto ao nível familiar e social. É, pois, nosso intuito dar um contributo à para a história (social) da infância esquecida na sociedade portuguesa, retratando-a no seu contexto temporal e dando-lhe voz. Incluímos nessa 'Outra infância' as designações de âmbito jurídico-social e penal, por exemplo: vadias, abandonadas, desamparadas, vagabundas, mendigas, órfãs, em perigo moral, delinquentes, infratoras, indisciplinadas, etc., ou seja, as desvalidas.

\section{A representação social da infância construída pela sociedade (conceções)}

As representações sociais constituem uma forma de conhecimento construído e partilhado pela coletividade (influência de Durkheim, Moscovici), oriundas de processos de socialização, geradoras de referentes de pertença e que deram origem a discursos onde se descrevem, simbolizam e categorizam os objetos ou os sujeitos com os quais se estabeleceram relações (ARRUDA, 2005). As representações fazem parte do estudo do imaginário (imagem, representação, conceção), entendendo este como construção social de arquétipos ou modelos paradigmáticos pelos quais a sociedade constrói a sua identidade, estabelece diferenças, legitima o poder e elabora modelos de 
formação para os cidadãos (JODELET, 1990). As representações e imaginários da infância conformam uma mentalidade, já que são construídos pela linguagem/comunicação e pelas interações quotidianas, fazendo parte da construção social e pelos quais se gera a socialização (primária) (MOSCOVICI, 1990).

As conceções relativas às representações da infância desvalida, ao longo do século XIX e início do século XX, mudaram com o tempo histórico. A sociedade criou conceitos e modelos para a infância, ao longo da história. Rousseau, no seu ambientalismo naturalista, descreve a infância como uma etapa especial da vida humana e refere a importância de preservá-la dos contactos nocivos da sociedade, considerando que a própria condição de infância, mesmo com as suas particularidades, tinha direito a um desenvolvimento livre e autónomo (MARTINS, 2006). O autor do 'Emílio' ressalta a importância do adulto, enquanto mediador do processo em que a criança tomará consciência da sua autonomia e dependência social. $O$ sentimento de infância deu-se, primeiramente, nas classes dominantes da sociedade ocidental (BEC et al., 1994). Entretanto, para as crianças pobres, mendigas e vadias, continuava-se a não reconhecer o significado de infância, ficando assim à mercê da própria sorte nessas situações e condições sociais (LOPES, 2010).

M. Sarmento (2000), reportando-se historicamente ao sentido atribuído à infância no século XVIII, considera que este se refletiu na imagem da criança e estendeu-se até ao início do século XIX: as crianças eram representadas fundamentalmente como seres humanos miniaturizados (adultos em miniatura) e como objeto de cuidado dos adultos, consideradas 'invisíveis', já que não tinham voz (direitos) nem vez (lugar social). Também Heywood (2004, p. 10) afirma que "[...] as crianças eram consideradas como sendo meramente adultos imperfeitos, subordinadas aos adultos, consideradas seres 'deficientes'[...]". O conceito de infância na sociedade ocidental nasce socialmente apenas quando os estudos consideram a especificidade infantil (estudos científicos sobre a criança e infância). Ora esta mudança de paradigma em relação à infância tem como uma das causas o decréscimo da mortalidade infantil, fator indicado como o mais decisivo para que se modificasse a relação afetiva entre os pais e a criança (THUILLIER, 2003). A imagem da infância, ao longo dos tempos, esteve dependente da família, dos contextos sociais, culturais, económicos, éticos, políticos, pedagógicos, judiciais, médicos e assistenciais. Por isso, ao fazermos uma representação da(s) infância(s), será importante compreendermos os significados atribuídos a ela(s) - construção social, nos seus múltiplos contextos/situações e condições delitivas, as quais mereceram medidas/respostas dos reformadores sociais, em cada período histórico.

De facto, a abordagem à infância em situação social e condições de conflito, crianças outrora designadas como 'anormais' e depois desvalidas ou em conflito social, implica uma clarificação conceptual, já que historicamente abrange uma multiplicidade de vocábulos associados 
a essas infâncias à margem, tidos por sinónimos, mas que expressam significados e situações existenciais e épocas diversas (LOPES; SÁ, 2008). São exemplos dessa 'Outra infância', que é o termo que adotamos neste estudo, as crianças desvalidas, vagabundas, vadias, pobres, mendigas, expostas, abandonadas, desamparadas, marginalizadas, infratoras e delinquentes.

$\mathrm{Na}$ nossa perspetiva, o pobre é alguém com falta de recursos, encontrando-se excluído dos hábitos, das normas sociais e dos costumes correntes na sociedade em que vive (MARTINS, 2006). A noção expressa por Townsend, citada na obra de Bruto da Costa (1998, p. 13), está de acordo com Martins, quando afirma que: “[...] os seus recursos [dos pobres] ficam tão seriamente abaixo dos controlados pelo indivíduo ou família, que eles ficam de facto excluídos dos padrões de vida, costumes e atividades [...]”. Evidentemente, a exclusão social (influência francófona), referente às situações sociais de pessoas/grupos desfavorecidos, vulneráveis e em precariedade, apresentava múltiplas privações no âmbito da educação, saúde, habitação, alimentação, vestuário, transporte, etc., e daí a pobreza, miséria, mendicidade, vagabundagem, marginalização, desemprego (ou emprego temporário) e outras situações de autoexclusão.

O conceito de exclusão social abrangia a pobreza, mas também incluía outras situações de ruturas ao nível social. O ser pobre não significava ser necessariamente excluído, pois podia ter restrições económicas e ainda assim manter laços afetivos, familiares e de amizade, como era o caso nas zonas rurais. Lembramos que Foucault (1978) atribuiu-lhe o significado de banimento, reclusão e expulsão, pois para este filósofo-a exclusão estava diretamente relacionada com as formas de distribuição de poder, e daí associar-se a controlo social e disciplinação, circulação de poder e hierarquia. Foucault (1978) refere a exclusão dos leprosos, dos ditos indivíduos 'anormais', com doenças venéreas, etc., explicando como ao longo dos processos históricos a figura de excluído integrou outros indivíduos na sociedade (representações), como os pobres, vagabundos, mendigos, abandonados e presidiários, incluindo as crianças/jovens.

Ora era nesse contexto de pobreza, abandono e marginalidade que viviam muitas crianças no arco temporal da nossa pesquisa (bairros dos centros urbanos), cenário esse que em Portugal dá origem ao surgimento de instituições asilares, casas de acolhimento, de educação e proteção, com medidas de proteção e de profilaxia social (influência da corrente higienista e eugenista), uma vez que aquelas crianças se poderiam tornar jovens vadios, infratores e delinquentes, simultaneamente improdutivos e perigosos para a coesão social. A tomada de consciência deste risco preparou o advento da LPI em 1911, em Portugal.

O Pe. António d'Oliveira (1923), mentor da Lei de Proteção à Infância em 1911 e primeiro Inspetor Geral dos Serviços Jurisdicionais de Menores na 1. ${ }^{a}$ República, explica, através das suas observações nas Casas de Detenção e Correção de Lisboa e Porto, a existência de termos 
diferenciados, consoante as características intelectuais, morais, físicas e comportamentais dessas crianças, sendo a condição relevante para estabelecer as estratégias de reeducação nos estabelecimentos de internação, criados para elas desde 1871 (casas de correção e colónias agrícolas correcionais), e alteradas por aquele diploma (Escolas de Reforma e Colónias agrícolas). Assim, aquele padre pedagogo do 'social' refere nos seus escritos as designações: extraviados (primitivamente bons e que, em certa altura da vida, se tornaram maus e perigosos, seja pelo contacto com certas companhias); retardados (termo proveniente da psicologia e muito usado por médicos e psicopedagogos como Aurélio da Costa Ferreira, diretor do Instituto MédicoPedagógico da Casa Pia de Lisboa); débeis (termo de Itard em que o intelecto se apresenta fraco e doente); broncos (o cérebro entorpecido por bebidas ou alimentação indevida para idade, e 'avariado' pelo abuso de determinados vícios); campónios; súcios e os magalas (menores que agiam mais pelo instinto e pelo hábito do que pela inteligência ou consciência, ou seja, eram 'os que atendem mas não entendem') (OLIVEIRA, 1923, p. 218-242).

\section{$2 \mathrm{~A}$ assistência (social) no âmbito dos dispositivos administrativos}

O país vivia em oitocentos muita pobreza e miséria, para além de elevados índices de analfabetismo, e sem assistência social, o que originava situações sociais inumanas e degradantes, em que as crianças sofriam as consequências desses flagelos sociais. O primeiro diploma legal sobre a assistência foi o decreto de 6/abril de 1835 que criou em Lisboa o Conselho Geral de Beneficência, como resultado da ineficácia das leis anteriores para travar a mendicidade e vagabundagem, estabelecendo um plano de melhoramento para a extinção e repressão dessas situações de mendicidade, vadiagem e abandono (RAMOS; CARVALHO; SILVA, 2018). Contudo, o diploma exclusivo da assistência à infância foi o decreto de 19/setembro/1836. Neste ano, Mouzinho de Albuquerque, impregnado de ideias liberais, apresenta um Relatório à Rainha sobre essas questões sociais e da ação do Conselho, propondo a criação do primeiro Asilo de Mendicidade em Lisboa, medidas repressivas para salvar os indigentes da miséria e provendo a sua subsistência. Mesmo não havendo, até finais do século XIX, dispositivos públicos específicos que tutelassem as questões assistenciais a nível nacional, os governos liberais propuseram diversas tentativas de controlo dessas situações adversas à coesão social, deixando às instituições de beneficência e filantrópicas o papel de as colmatar (LOPES; PAIVA, 2010; PEREIRA, 2012).

Na verdade, a proteção à infância era uma incumbência da Junta Geral do distrito já referida no Código Administrativo de 1836, cabendo ao governador vigiar a observância das leis relativas aos expostos e tomar providências policiais sobre mendigos, vadios e vagabundos (RAMOS; CARVALHO; SILVA, 2018). Desde 1866 (Ministro do Reino Martens Ferrão), cabia aos 
governadores civis conhecerem essas situações e prover vários aspetos do serviço público, para além da elaboração de Relatórios. O Código Administrativo de 1842 atribuía essa incumbência ao governador civil de superintender os estabelecimentos de beneficência promovendo o seu melhoramento e regulando a sua administração (fiscalização e anulação de deliberações das Juntas de Paróquia e até a sua dissolução). Só mais tarde os Códigos Administrativos de 1878 (governador civil tem a tutela administrativa) e de 1886 (repressão da mendicidade e vadiagem) atribuíram às Juntas gerais esse papel regulador e de dirigir, ao nível distrital, a administração dos expostos e crianças desvalidas e/ou abandonadas (art. ${ }^{\circ} 53$ do Código 1878) ou deliberar sobre essas administração dos menores de 7 a 18 anos, incluindo subsídios para a criação de asilos ou escolas distritais de artes e ofícios, onde se lhes pudesse ministrar a educação ( $\operatorname{rrt}^{\circ} 54$ do Código de 1886) (SERRA, 1988). Pelos finais de oitocentos, surgem soluções alternativas à 'Roda' e medidas repressivas ao abandono, no âmbito da competência municipal, com administração dos expostos e da infância desvalida ou abandonada até aos 7 anos, ficando depois dessa idade a cargo da Junta Geral do distrito (art. 117 do Código de 1886). Portanto, naqueles normativos, estabeleciam-se as competências em matéria de assistência à infância, para além de se subsidiar os estabelecimentos distritais de beneficência, de instrução e educação.

Em 1901, as competências fixadas nos Códigos administrativos ampliam-se (funções de vigilância e inspeção), no domínio da assistência à infância (art. ${ }^{o} 292$ do Código de 1895) e promoção de prestação de socorros, em especial de doenças, e ainda a obrigação de fundar e subsidiar estabelecimentos de beneficência municipal (SERRA, 1988).

Paralelamente, neste período histórico, a criança e a sua infância passaram a ser alvo de estudos de diversas áreas científicas (biologia, medicina, psiquiatria, direito, criminologia, pedagogia, psicologia, etc.). Por influxo das correntes positivistas, surgem grupos de associação ou sociedades preocupadas com o "estatuto da criança' e com a sua 'salvação', especialmente a 'Outra infância'. Isto era materializado através dos asilos, casas de correção, recolhimentos, escolas agrícolas, institutos médico-pedagógicos, etc. No século XX, a criança passou a ser um objeto quantificável e de investigação, convertida em conteúdos culturais, educativos e morais, num mundo ou em espaços próprios (escolar, social), disciplinados e regulados. Contudo, toda a infância que por várias razões e situações (familiares, sociais, educativas, culturais, económicas e deficiências) não seguia essa normatização imposta considerava-se anormal ou à margem da sociedade e, assim, emerge a 'Outra infância' com necessidade de medidas de proteção e (re)educação. De facto, só no início do século XX se reconheceu a necessidade de se legislar para garantir a proteção e prevenção daquela infância e, ainda, regular o trabalho infantil, reforçar a 
obrigatoriedade escolar elementar, alargar a assistência social pública, criar creches, etc. (FONTE, 2004; PEREIRA, 2012).

A Lei de Proteção à Infância de 1911 opõe-se ao modelo de justiça penal existente para os menores (correcional e repressiva), já que estes eram punidos nos mesmos moldes dos adultos, dando espaço a uma 'cura reeducativa e profilática'. Essas respostas assistenciais e repressivas unem-se aos modelos práticos de correção, regeneração e reeducação, de âmbito médicopedagógico. A assistência à 'Outra infância' esteve marcada pela ação dos estabelecimentos das Misericórdias e Casa Pia de Lisboa (criada por Pina Manique a em finais do século XVIII) com a função de acolher, assistir, regenerar e educar.

\section{Instituições de internação para acolher, assistir e educar a infância desvalida}

O início de alguns serviços de proteção e internamento à infância pobre/órfã, abandonada e desvalida remonta à criação das Misericórdias, marcando o começo da criação de estabelecimentos assistenciais e de educação (hospícios, recolhimentos, orfanatos, seminários, colégios, asilos, etc.), sendo que, a partir do século XVI, as Câmaras Municipais passaram a ter o encargo dos expostos, pobres e abandonados. No século XVIII há uma intervenção direta neste problema social, por parte do Estado, tendo as Misericórdias, em especial as de Lisboa e do Porto, a finalidade de acolher e assistir (base na caridade) criando estabelecimentos de internato. Já no século XIX surgem, a partir de 1834, as instituições asilares, reguladas pelo governo e organizadas por regulamentos de internação, provenientes de filantropos, beneméritos, com apoio público e do governo (Juntas distritais).

As instituições de acolhimento e proteção ajustam-se à perspetiva de E. Goffman (1974), que refere que as instituições são espaços fechados, onde um determinado número de indivíduos vive-separados da sociedade e do contacto com o mundo exterior, sendo os mesmos moldados pelas operações de rotina, recebendo regras e instruções (CALDEIRA, 1993). Goffman (1974) considera o internato uma organização social, um espaço rodeado por barreiras (físicas, psicológicas) e por valores culturais, que tendem a produzir o modo de ver e agir dos internados. Ou seja, cada internado terá sobre determinado aspeto a visão promovida pelos valores culturais da organização. Os internados, ao entrarem na instituição, despojavam-se dos seus bens materiais, com a finalidade de apagar a sua história passada, submetendo-se a um estilo de vida de governação e internação, baseado nas regras e normas e daí as várias formas de poder descritas por Foucault (1998).

Nos estabelecimentos de assistência, a instrução primária era obrigatória e a música constituía um elemento reeducativo, assim como a educação física e as aulas de desenho, mas as 
vantagens da higiene do corpo e da educação moral somente no século XX começaram a existir nos internatos. A educação moral e religiosa também era desenvolvida no internato: cabia ao capelão promover nos menores os valores morais e religiosos, simultaneamente com os exercícios espirituais e catequéticos, "[...] o que era uma peça fulcral da reabilitação moral do menor [...]" (MARTINS, 2015, p. 321). A educação ministrada nos estabelecimentos asilares ou outros congéneres, para as crianças após os 6 ou 7 anos de idade, em regime de internato, baseava-se no nível da instrução primária, contemplada com o ensino da religião e da moral, como forma de as crianças interiorizarem as normas. A educação tinha como objetivo transformar as crianças em indivíduos responsáveis e, desde cedo, elas deveriam adquirir rudimentos de leitura, escrita e cálculo, assim como bases da doutrina cristã, lendo a Bíblia (em latim), adquirir hábitos de higiene e ainda aprender um ofício. De facto, esta aprendizagem profissional destinava-se aos maiores de 14 anos, dirigidos por professores e "mestres-de-oficinas"; tinha um papel importante na reeducação no internato: “[...] As oficinas mais comuns naqueles estabelecimentos de reeducação eram a alfaiataria, a carpintaria, mecânica, serralharia, desenho artístico, encadernação, gráfica e tipografia, marcenaria, sapataria, etc. [...]” (MARTINS, 2015, p. 326).

Os estabelecimentos em regime de internato eram regidos por um Regulamento interno, conjunto de regras/normas, com a função de tornar o comportamento dos internos homogéneo para a convivência, propondo estratégias de os 'corrigir-educar' moralmente e, assim, se acentuou o caráter preventivo, a ação social e o tratamento médico-pedagógico.

Este modelo de educação e ensino em instituições de internação fechadas desenvolveu-se nas instituições religiosas e perdurou até ao século XX. A punição física era um dos métodos de correção ou (re)educação que as instituições de internação usavam como estratégia de controlo dos internos. A disciplina, o ambiente educativo e a pedagogia correcional de internato, até ao início do século XX, era rígida e regulada pelos regulamentos internos. A conceção de internato como sistema educativo isolado invisibilizava as crianças pelo corte com o exterior: os internados estavam o tempo todo das suas vidas à mercê dos princípios do projeto educativo e de quem o dirigia (diretor). A disciplina e a ordem tinham como finalidade educativa despertar o interesse pelas tarefas e obrigações, incutir hábitos de trabalho e o sentido de responsabilidade.

Em relação às práticas quotidianas nos internatos, Certeau (1994, p. 100) define quotidiano como "[...] aquilo que nos é dado cada dia (ou que nos cabe em partilha), o que nos pressiona dia após dia, o que nos oprime, pois existe uma opressão do presente. É aquilo que nos prende intimamente, a partir do interior [...]". Na vida quotidiana lidamos com 'táticas e estratégias' (mecanismos de poder), cujas práticas são como o modo de ação, operação feita pelo indivíduo no processo de interação social. Ou seja, para Certeau, é na relação social que é determinado o 
indivíduo e, por isso, só é possível uma compreensão mais exata deste a partir das suas práticas e relações sociais. Certeau (1994, p. 101) descreve estratégia como “[...] o cálculo (ou manipulação) das relações de forças, que se torna possível a partir do momento em que o sujeito de querer ou poder (empresa, uma instituição científica, uma cidade) pode ser isolada [...]”. A estratégia vinculava-se ao poder hegemónico dominante dos fortes (diretores, funcionários dos estabelecimentos), que a usavam como forma de convencimento, de argumentação e de intimidação para dominar sobre os fracos (internados). Esta ação dos que têm poder, a estratégia, demanda local próprio, exige espaço, que pode ser institucional (escola, internato); físico (sala de aula), e mesmo um lugar simbólico (a posição do professor na relação pedagógica). Estes locais regidos por regras e normas pretendem assegurar a estabilidade das ações dos indivíduos, que são submetidos à observação e ao controlo. Esta "arte do forte" é expressa em regulamentos, leis e demais normativos, que disseminam o controlo da ação dos indivíduos no espaço institucional.

Em suma, no século XX havia três tipos de estabelecimentos destinados à assistência, regeneração moral, correção ou (re)educação, segundo a origem e tipologia da infância detida (MARTINS, 2006, p. 121-126): estabelecimentos públicos, dependentes dos Serviços Jurisdicionais e Tutelares de Menores, para os menores delinquentes, indisciplinados, abandonados e vadios com idade inferior aos 16 ou 18 anos; os públicos e privados destinados às crianças 'em perigo moral', abandonadas, órfãs e pobres, sob o controlo da Direção-Geral de Assistência (creches, asilos, acolhimentos, colégios e/ou estabelecimentos da Misericórdia e da Casa Pia de Lisboa, escolas profissionais de regeneração, etc.), onde permaneciam até aos 18 anos; e os particulares administrados por associações beneméritas, legados de filantropos e organismos sociais e religiosos.

De facto, houve avanços relativamente aos modelos institucionais de internamento, de institucionalização, de intervenção e de práticas de atendimento, apesar de persistirem alguns resquícios da intervenção assistencialista e autoritária no âmbito da família. As instituições do tipo internato caíram em desuso e o tema deixou de ser discutido, como se o problema tivesse sido resolvido, mas não foi. As denúncias de violência associadas às instituições que acolhiam essas crianças/jovens e a intensa circulação das crianças entre as instituições de acolhimento e a escola e a comunidade atestam a necessidade de um tipo específico de atendimento.

\section{Ideias (IN)conclusivas}

Não há uma infância, mas sim muitas infâncias e todas elas diferentes (diferenciação). Neste estudo analisamos a 'Outra infância', aquela que não tinha um processo de normatização na sociedade e que foi motivo de reformas sociais, respostas e medidas assistenciais, (re)educativas e institucionais. Esta pluralidade de dispositivos dependeu do tempo histórico. A infância como 
categoria concetual ocupava espaços, apresentava representações sociais, diferentes visões/discursos (visíveis, invisíveis), segundo os enfoques e olhares de análise. A assistência e (re)educação à infância, nos-séculos XIX e parte do século XX, revelou que as crianças nascidas em situação de pobreza, precariedade e/ou em famílias com dificuldades, famílias numerosas, em miséria social ou incapacitadas para as educar, eram acolhidas (asilos, orfanatos e recolhimentos) para serem assistidas e educadas, enquanto as vadias, infratoras com comportamentos antissociais e delinquentes eram detidas pelos dispositivos jurídico-penais estabelecidos na época e colocadas em casas de correção ou colónias agrícolas correcionais. Só com a publicação da Lei de Proteção de Infância de 1911, que originou o direito tutelar de menores, essas infâncias, segundo a sua tipologia de delito ou situação social, foram encaminhadas para instituições de assistência, salvo as que eram entregues às famílias ou ficavam submetidas a regime de vigilância (curadores). Assim, os dispositivos da proteção, prevenção e promoção dessas infâncias materializou-se a partir do século XX.

Apesar de haver algumas estatísticas dos boletins oficiais ou nos registos de detenção dos documentos das Tutorias Centrais de Infância (Lisboa, Porto, Coimbra, incluindo os respetivos Refúgios) e Comarcas, merecedoras de abordagens em alguns dos nossos estudos anteriores, sabemos, no entanto, que várias gerações de crianças/jovens passaram as suas infância e adolescência internadas em grandes instituições fechadas (terminologia de Goffman), designadas por 'internatos', orfanatos, asilos, Casas de Correção e Detenção (Lisboa em 1871 e depois Porto -Vila do Conde), Colónias Agrícolas Correcionais (por exemplo, de 1880 a de Vila Fernando/Elvas), Escolas de Reforma (Lisboa em 1911) e, posteriormente reformatórios, as quais funcionavam com uma disciplina interna rigorosa e modelos assentes em métodos correcionais (semelhantes a prisões, cárceres, do século XIX), médico-pedagógicos, psicopedagógicos e reeducativos. Ora, tudo isto ocorreu a despeito do facto de que a internação desses menores (termo jurídico relativo à idade de menoridade) aparece principalmente na literatura jurídica social e pedagogia correcional ou pedagogia social e, por isso, gerou-se uma verdadeira 'cultura da institucionalização' para aquelas tipologias de crianças/jovens detidas e submetidas ao regime tutelar da jurisdição de menores desde os inícios do século XX.

Lembramos que este fenómeno de institucionalização da 'Outra infância', as crianças/jovens que antigamente eram referidas como 'anormais', devido a não percorrerem uma normalização ou normatividade imposta pela sociedade ou sistema (social, educativo), hoje são as de situação de 'risco' ou 'em perigo'. Devemos ter presentes os fatores socio-históricos e políticoideológicos, que constringiam ou implicaram políticas sociais, muitas delas não atenuaram ou suprimiram essas situações sociais a que eram vertidos esses ‘frágeis' seres humanos e, por isso, 
permaneceram relegados de boa parte da sociedade, pois a outra mantinha vestígios de benemerência, filantropia e caridade social e religiosa.

Historicamente, as práticas de internamento enraizaram-se nos dispositivos de 'proteçãoprevenção-promoção' aos menores, resistindo temporalmente a mudanças e, por isso, efetuaramse de forma lenta. Em parte, porque as demandas que implicaram um número incontável de crianças/jovens aos internatos não foram devidamente enfrentadas ao nível das políticas públicas (sociais, assistenciais e educativas). Infelizmente, a demanda persistiu e possivelmente aumentou em vários momentos histórico-temporais, dadas as condições das famílias, da pobreza/miséria social, analfabetismo e falta de assistência social de grande parte da população. Ou seja, não foram criadas alternativas que efetivamente evitassem a separação dessas crianças/jovens das famílias, do meio e da comunidade. Isto ocorreu devido ao facto de que, no século passado, apareceram propostas de mudança em consonância com o movimento internacional de garantia dos direitos da criança. Assim, está por fazer a História da Assistência à Infância ou História das Instituições Educativas não formais para a Infância Desvalida em Portugal, de forma sistemática até ao presente.

\section{Referências}

ARRUDA, A. Pesquisa em representações sociais: a produção em 2003. In: MENIN, M. M. S.S. \& SHIMIZU, A. M. (orgs.), Experiência e representação social. São Paulo: Casa do Psicólogo, 2005, p. 59-92.

BEC, C. (dir.) et al. Philanthropies et politiques sociales en Europe (XVIII'-XX'--siècles). Paris: Anthropos, 1994.

CALDEIRA, M. ${ }^{a}$ de Fátima C.G.E.S. De meninos se faz̧em homens: Assistência infantil e juvenil na cidade de Lisboa durante a 1. ${ }^{a}$ República. Tese (Mestrado em Ciências Sociais e Humanas) Fac. Ciências Sociais e Humanas - Univ. Nova de Lisboa, Lisboa, 1993.

CERTEAU, M. A invenção do cotidiano: Artes de fazer. Vol.1. Petrópolis: Vozes, 1994.

COSTA, Alfredo Bruto da et al. A pobreza em Portugal. Lisboa: Caritas, 1985.

COSTA, Alfredo Bruto da. Exclusões sociais. Lisboa: Gradiva, 1998.

FONTE, T. Afonso da. No limiar da honra e da pobreza: a infância desvalida e abandonada no Alto Minho (1698-1924). Tese (Doutoramento em Ciências Sociais) -Instituto de Ciências Sociais da Universidade do Minho, Braga, 2004.

FOUCAULT, M. História da loucura na idade clássica. São Paulo: Perspetiva, 1978.

GOFFMAN, E. Manicómios, Prisões e Conventos. São Paulo: Perspectiva, 1974. 
GUESLIN, A. L'Invention de l'économie sociale : Le XIX siècle français. Paris: Economica, 1987.

HEYWOOD, Colin. Uma história da Infância: Da idade Média à época contemporânea no Ocidente. Porto Alegre: Artmed, 2004.

LOPES, M. A Antónia. Proteção social em Portugal na Idade Moderna: Guia de estudo e investigação. Coimbra: Imprensa da Univ. de Coimbra, 2010.

LOPES, M. ${ }^{a}$ A.; SÁ, Isabel dos Guimarães. História breve das misericórdias portuguesas. Coimbra: Imprensa da Univ. de Coimbra, 2008.

LOPES, M. A Antónia; PAIVA, J. Pedro (dirs.). Portugaliae Monumenta Misericordiarum. - Vol. 8 Tradição e modernidade: O período da Monarquia Constitucional -1834-1910. Lisboa: União das Misericórdias Portuguesas, 2010 p. 7-30.

MARQUES, A.H. de Oliveira; RODRIGUES, L. N. A sociedade e as instituições sociais. In: MARQUES, A.H.O.; SERRÃO, J. (dirs.) - Nova História de Portugal (Vol. XI). Lisboa: Presença, 1991, p. 187-239.

MARTINS, A. M. a de Castro. Génese, emergência e institucionalização do serviço social português. Lisboa: FCG - Fundação para a Ciência e Tecnologia, 1999.

MARTINS, E. C. A infância desprotegida portuguesa na primeira metade do século XX. Revista Infância e Juventude, $\mathrm{n}^{\circ}$ 4, outubro/dezembro, 2006, p. 93-130.

MARTINS, E. C. Infância Marginalizada e Delinquente na $1^{a}$ República (1910-1926). De Perdidos a Protegidos...e Educados. Lisboa: Palimage, 2015.

OLIVEIRA, Pe. A. d'. Deixemos os pais e cuidemos dos filhos. Lisboa: Ed. do Autor, 1923

PEREIRA, D. O. R. As politicas sociais em Portugal (1910-1926). Lisboa: Faculdade de Ciências Sociais e Humanas - Univ. Nova de Lisboa, 2012.

RAMOS, R. ; CARVALHO, J.M.; SILVA, I. C. A Monarquia Constitucional dos Braganças em Portugal e no Brasil (1822-1910). Lisboa: Publ. Dom Quixote, 2018.

SARMENTO, M.J. A Infância: Paradigmas, Correntes e Perspetivas. Braga: Instituto de Estudos da Criança - Universidade do Minho, 2000.

SERRA, J. B. As reformas da administração local de 1872 a 1910. Análise Social, vol. XXIV (103104), $1988\left(4^{\circ}, 5^{\circ}\right)$, p. $1037-1066$.

THOMPSON, J. B. Ideologia e Cultura Moderna. Teoria Social Crítica na Era dos meios de comunicação de massa ( $9^{\mathrm{a}}$ ed.). Petrópolis, RJ: Vozes, 2011.

THUILLIER, G. Principes de l'bistoire de la protection sociale. Paris: Comité d'Histoire de la Sécurité Sociale, 2003. 